\title{
Factors Associated with Early Initiation of Complementary Feeding in Bishoftu Town, Oromia, Ethiopia
}

\author{
Gizaw Gemechu Deme1, Shimelis Adugna Bekele², Mesele Damte Argaw³*, \\ Yemane Berhane ${ }^{4}$ \\ ${ }^{1}$ College of Veterinary Medicine and Agriculture, Addis Ababa University, Bishoftu, Ethiopia \\ ${ }^{2}$ Zaf Pharmaceuticals PLC, Addis Ababa, Ethiopia \\ ${ }^{3}$ Private Health Sector Program, Addis Ababa, Ethiopia \\ ${ }^{4}$ Addis Continental Institute of Public Health, Addis Ababa, Ethiopia \\ Email: gizawgemechu@yahoo.com, adugna27@gmail.com, ${ }^{*}$ mdamte5@gmail.com, \\ yemaneberhane@gmail.com
}

Received 2 September 2015; accepted 19 September 2015; published 25 September 2015

Copyright (C) 2015 by authors and OALib.

This work is licensed under the Creative Commons Attribution International License (CC BY). http://creativecommons.org/licenses/by/4.0/

(c) (i) Open Access

\section{Abstract}

Background: Early initiation of complementary feeding which was widely documented in many countries exposed infants to increased risk of morbidity and mortality. The purpose of this study was to assess the prevalence of early initiation of complementary feeding and associated factors in Bishoftu Town, Oromia, Ethiopia. Methods: An institutional based cross-sectional study design was conducted from January-February 2015 among 422 mothers of infant aged less than 6 months selected from four public health facilities. Prevalence of early initiation of complementary feeding was determined using "recall since birth" method. Multi-variable logistic regression analysis was employed to control confounders in determining association between early initiation of complementary feeding and selected independent variables. Adjusted Odds Ratio (AOR), 95\% Confidence Interval (CI) and $\mathbf{P}<0.05$ were used to claim statistical significance. Results: The prevalence of early initiation of complementary feeding was $32.9 \%(137 / 416,95 \% \mathrm{CI}: 28.0,37.0)$. The odd of mothers with delayed initiation of Breastfeeding was 4.76 times higher to expose their child to early complementary feeding than women who initiated breastfeeding within one hour after delivery with AOR $4.76(95 \%$ CI; $2.48-9.13$, P value $<0.001)$. This finding was a little higher than estimates of other studies. The odds of house wife mothers and mothers who delivered at health institution had $64 \%$ and $74 \%$ lower risk to early initiate complementary feeding than employed and home delivered mothers with AOR 0.34 (95\% CI; 0.21, 0.55) and AOR 0.26 (95\% CI; 0.08, 0.89), respectively. The odd of mothers who lacked knowledge on the duration of optimum breastfeeding duration was 3.91 times higher to practice early initiation of complementary feeding than who correctly knew it with AOR 3.91 (95\%; 2.33, 6.54, P-value 0.001). Conclusions: Almost one third of mothers initiated early initiation of complementary feeding at four months of their child's age.

${ }^{*}$ Corresponding author.

How to cite this paper: Deme, G.G., Bekele, S.A., Argaw, M.D. and Berhane, Y. (2015) Factors Associated with Early Initiation of Complementary Feeding in Bishoftu Town, Oromia, Ethiopia. Open Access Library Journal, 2: e1949.

http://dx.doi.org/10.4236/oalib.1101949 
Encouraging all mothers to initiate breastfeeding within an hour, providing counseling service on recommended six-month duration of exclusive breastfeeding was recommended.

\title{
Keywords
}

\author{
Early Initiation, Complementary Feeding, Factors, Ethiopia
}

\author{
Subject Areas: Public Health
}

\section{Introduction}

Globally, there has been a progress in improving child survival. Though the world promised to reduce child death by two third from the level recorded in 1990 by 2015, in the last two decades the under-five children death was decreased only by half by 2013: from 12.7 million to 6.3 million. To keep the momentum of these achievements nearly 180 governments have pledged to scale up efforts to accelerate in declining maternal, neonatal and child deaths [1] [2].

As a global public health recommendation infants should be exclusive breastfed for the first half-year of life to achieve the optimal growth, development and health. Thereafter, to meet the evolving nutritional requirement infants should receive nutritionally adequate and safe complementary foods with continued breastfeeding up to two years or beyond [3]-[5]. Optimal feeding practice in the first two year of life is crucial for the survival and health of infants, and has long-term consequences in later life.

Poor breastfeeding and complementary feeding practices have been widely documented in the developing countries. The prevalence of exclusive breastfeeding in the first six months after delivery in developing countries was 39\%; it was even less in Africa which stood at just 25\%. Additionally, $6 \%$ of infants in developing countries are never breastfed [6].

According to 2011 the Ethiopian Demographic Health Survey (EDHS) report, 27\% of mothers provided water, butter, and various types of food to feed their children, thereby reducing the percentage of exclusively breastfeed and increasing the percentage of receiving complementary food at very young age [6]. Recent local studies in Mekelle Town of Tigray Region, Debre Berhan District of Amhara Region, Oromia Regional State Jima Arejo Area and Goba District revealed that the prevalence of early initiation of complementary feeding was 37.2\%, 31.4\%, 42.9\% and 28.7\%, respectively [6]-[9]. Another study conducted in Southern Nation, Nationalities and Peoples Region [SNNPR], in Kamba district by Agedew et al. found higher prevalence of early started complementary feeding practice (59.6\%) [10].

Predictors of early initiations of complementary feeding were maternal age, substance (cigarette smoking) [11], educational status, family size, and economic variables [12]. But local evidence related to factors influencing early initiation of complementary feeding practice in Ethiopia is scarce. Agedew et al. conducted a community based study in a rural set up using children aged 6 to 24 months [10]. This study reported maternal age, occupation, postnatal services and maternal health status as a major factor influencing early initiation of complementary feeding for infants in the study area. In light of this, it is relevant to determine unbiased prevalence of early initiation complementary feeding and investigate factors influencing this practice in urban population among infants who are attending four public health facilities for vaccination services in Bishoftu Town of Oromia Region, Ethiopia.

\section{Methods}

\subsection{Study Setting}

Bishoftu is located in Oromia National Regional State, East Shoa Zone at a distance of $47 \mathrm{Km}$ from Addis Ababa, the Capital City of Ethiopia. It is one of the reform towns in the region and has a city administration, municipality and nine kebeles, lowest administrative unit. The 2007 national census reported a total population of Bishoftu is 99,928 of whom 47,860 were men, 52,068 were women and 3177 were infants. Bishoftu has got one hospital and three health centers. The hospital logs roughly 154,000 visits a year with 4000 annual admissions. 


\subsection{Study Design}

Institutions based cross sectional study was conducted among mothers of infant aged less than six months who are selected in Bishoftu town at four public health facilities from January to February 2015 G.C.

\subsection{Study Population}

Source of population comprised of mothers with infant aged less than six months who were attending four public health facilities for penta-valent three immunizations in Bishoftu town, of Oromia Region, Ethiopia.

\subsubsection{Inclusion Criteria}

All voluntary mothers of infant aged less than six months coming to the four public health facilities for pentavalent three immunizations.

\subsubsection{Exclusion Criteria}

Mothers who couldn’t verbally communicate were excluded for the study.

\subsection{Sample Size}

Sample size for this study was calculated using single population proportion and assuming that the proportion of early initiation of complementary feeding for infants less than six months of age was $59.6 \%$ documented by Agedew et al. in Kamba district of South West Ethiopia [10] margin of error 5\% and 95\% confidence level. Therefore, $n=370$, considering $14 \%$ for refusal and incomplete data $(n=370+52=422)$.

\subsection{Sampling Procedure}

The sampling unit was taken from each four public health facilities based on their predetermined client flow rate. To allocate the study subjects, first the average numbers of clients who visit for penta-valent three vaccinations were estimated by referring client registration book/record prior to data collection. Proportion to population size was made. Finally mothers' infant pairs fulfilling the criteria were recruited based on their time of arrival at the survey site. The samples were collected from four public health facilities based on proportional allocations.

\subsection{Data Collection Tool \& Procedure}

The questionnaire was adapted from the Ethiopian Demographic and Health Survey (EDHS) [8] and WHO recommended tools for the assessment Infant and Young child feeding practices for national surveys [13]. To proceed with data collection the questionnaire originally prepared in English language were translated in to local languages Afan Oromo and Amharic and then back to English for consistency. The interview guide was pretested using $12 \%$ of estimated sample size among mother infant pair visiting public health facilities for vaccination services in nearby town called Dukem, Oromia Region.

Data were collected on socio demographic characteristics, maternal health service uptake and infant feeding practice using "recall since birth" method. Face to face interview was conducted with mothers who visited health facility for penta-valent vaccination service for their child in four public health facilities. The data collectors were four female nurses, who have diploma or degree level of education and who were working in Modjo town were recruited and trained for one day on objectives, relevance of the study, confidentiality, informed consent, and techniques of interview.

\subsection{Variable of Study}

\subsubsection{Dependent Variable}

Early initiation of complementary feeding.

\subsubsection{Independent Variable}

Age of the mothers, age of the child, gender of the baby, educational status of the mothers, occupation of the mothers, marital status of mothers, number of life births, antenatal follow up, place delivery, ownership of radio and television, knowledge and practices of mothers. 


\subsection{Operational Definitions}

According to WHO (2008) the term complementary feeding, reserved to describe appropriate feeding practices in breastfed children 6 - 23 months of age. Complementary foods are foods other than breast milk or infant formula liquids, semisolids, and solids introduced to infants to provide nutrients [14] [15]. In this study a baby received foods or fluids other than breast milk preceding the survey was considered as a child early exposed to complimentary food.

Delayed breastfeed initiation: If breast feeding were not initiated immediately after birth (within an hour) it is considered as late breast feeding initiation [14] [15].

\subsection{Data Quality Control}

One day long training and pretesting was arranged for data collectors and supervisors. Moreover, the questionnaires were pre-tested at Dukem Health Center. The data collection tools were amended based on the finding of the pilot test. Supportive supervision was conducted during the beginning of the actual data collection by the investigator. Every questionnaire was checked for completeness and supervisors were providing feedback on the quality of the data on daily basis. In addition, filled questionnaires were cleaned and coded to enter into the computer by the data encoder.

\subsection{Data Management and Analysis Procedure}

Data were entered using EPI info statistical software 3.5.1 (CDC, Atlanta, Georgia, USA) and exported to Statistical Package for Social Science (SPSS) research (SPSS-IBM-version 20) for analysis. Cleaning was made using frequencies and univariate analysis. Percentages, frequency distributions and measures of central tendency and measures of dispersion were used for describing data. The investigator used "recall since birth" method to determine the prevalence of early initiation of complementary feeding among infants attending health facilities for penta-valent three vaccinations. Bivariate logistic regression was computed to identify the association of independent and dependent variables. Finally, independent variables found to have P-value $\leq 0.2$ were entered to multivariate logistic regressions to control the effect of confounding.

\subsection{Ethical Consideration}

Ethical approval was obtained from institutional review board of Adama Science and Technology University and Addis Continental Institute of Public Health (ACIPH). Permission to undertake the study was obtained from the Hospital, Health Centers, and Administrative Authorities. Informed consents were also obtained from the study participants after explaining the purpose of the study. Participation of all respondents in the survey was strictly voluntary. All information obtained from the respondent was anonymous and confidential.

\section{Results}

\subsection{Socio-Demographic Characteristics of Study Participants}

In this study a total of 422 mothers with their index were enrolled, resulting a response rate of $100 \%$. The mean $( \pm$ SD) age of the mothers was 27 years ( \pm 4.66$)$. Slightly higher than one third of mothers $155(36.74 \%)$ were attended primary level of education. The most citied occupation of mothers $253(60 \%)$ were house wife. And a little higher than half of respondents 244 (57.8\%) were deliver their babies in hospital. The age of infants ranged from 3 to 4 months. Slightly lower than half of the children 196 (46.4\%) were males. In terms of birth order around half $200(47.4 \%)$ of them were first child for their family (Table 1).

\subsection{Utilization of Maternal Health Service}

Three hundred eighty four (91.0\%) of mothers had received at least a single antenatal care services for the index infant. Slightly lower than half $47.4 \%$ of mothers were premipara, close to half 21 (51.2\%) were multipara and the rest $6(1.4 \%)$ were grand multipara mothers. The majority $96.4 \%$ of all mothers had institutional delivery and 15 (3.6\%) of mothers reported home delivery. 
Table 1. Socio-demographic characteristics of mothers and their index infant, Bishoftu, February 2015.

\begin{tabular}{|c|c|c|}
\hline Characteristics & No. & $\%$ \\
\hline \multicolumn{3}{|l|}{ Age of mothers in years } \\
\hline $18-19$ & 25 & 5.9 \\
\hline $20-24$ & 66 & 15.6 \\
\hline $25-29$ & 214 & 50.7 \\
\hline $30+$ & 117 & 27.7 \\
\hline \multicolumn{3}{|l|}{ Education status of mothers } \\
\hline Illiterate & 48 & 11.4 \\
\hline Primary & 155 & 36.7 \\
\hline Secondary & 138 & 32.7 \\
\hline Higher education & 81 & 19.2 \\
\hline \multicolumn{3}{|l|}{ Occupation } \\
\hline Government & 58 & 13.7 \\
\hline Private business & 82 & 19.4 \\
\hline House wife & 253 & 60.0 \\
\hline Student & 5 & 1.2 \\
\hline Others & 24 & 5.7 \\
\hline \multicolumn{3}{|l|}{ Age of infant in months } \\
\hline$<4$ & 402 & 95.3 \\
\hline $4+$ & 20 & 4.7 \\
\hline \multicolumn{3}{|l|}{ Infant birth order } \\
\hline First & 200 & 47.4 \\
\hline Second & 125 & 29.6 \\
\hline Third & 76 & 18 \\
\hline Fourth & 15 & 3.6 \\
\hline$>4$ & 6 & 1.4 \\
\hline \multicolumn{3}{|l|}{ Baby’s gender } \\
\hline Male & 196 & 46.4 \\
\hline Female & 226 & 53.6 \\
\hline \multicolumn{3}{|l|}{ Place of birth } \\
\hline Home & 15 & 3.7 \\
\hline Government hospital & 244 & 57.8 \\
\hline Government health center & 117 & 27.7 \\
\hline Health post & 17 & 4.0 \\
\hline Private clinic & 29 & 6.9 \\
\hline
\end{tabular}

\subsection{Complementary Feeding}

Of all 416 (98.6\%) mothers who had breastfed their child, at the time of the interview 32.9\% (137/416; 95\% CI: $28.0 \%-37.0 \%$ ) mothers had started complementary for their child. This finding revealed, in the study area, one third of infants were exposed to complementary food at three to four months of age. The foods/drinks given to 
breastfeeding child were milk other than breast milk $74.5 \%$, infant formula $65.0 \%$, plain water $5.1 \%$ and the others were constituted by fresh butter, glucose water and sugar salt solution (Figure 1).

\subsection{Factors Reported in Association with Early Initiation of Complementary Feeding}

A logistic regression model was used to examine factors associated with early initiation of complementary feeding as dependent variable. Multi-variable logistic regression analysis was computed and four predictor variables of early initiation of complementary feeding were identified. The odds of mothers with delayed initiation breastfeeding was 4.76 time higher to start early complementary feeding for their child than women who initiated breastfeeding within an hour with AOR 4.76 (95\% CI; 2.48 - 9.13, P value < 0.001). The odds of mothers with employed mothers and mothers who gave birth in health facilities were $64 \%$ and $74 \%$ less likely exposed their infants for complementary feeding than their counterpart with AOR 0.34 (95\% CI; 0.21, 0.55) and AOR 0.26 (95\% CI; 0.08, 0.89), respectively. The odds of mother who lack knowledge on the recommended optimum duration of exclusive breastfeeding for a child was 3.91 times higher to start complementary feeding than mothers who knows it with AOR 3.91 (95\%; 2.33, 6.54, P-value 0.001) (Table 2).

\section{Discussions}

In this study, the prevalence of early initiation of complementary feeding is $32.9 \%$ with the median age of infant 3 months. Mothers who are employed, who gave birth at home, lack the knowledge of optimum duration of exclusive breastfeeding and delay breastfeeding initiation were the factors identified for early initiation of complementary food.

The 32.9\% of estimation was found in line with the national prevalence 27\% [6], 31.4\% in Debre Berhan district of Amhara Region [9] and Oromia region Goba district which was 28.7\% [8] and relatively there was similar finding in North Ethiopia Mekelle (37.2) town [5]. But it was much lower than $42.9 \%$ documented in Jima Arjo district [7] of Ethiopia which was studied at community level. And 59.6\% documented by Agedew et al. in Kamba district, Gamo Gofa Zone of South West Ethiopia [10]. This difference could be explained by the study design and enrolled study subjects or age of infants enrolled in the studies. Since in this study, we estimated the prevalence of early initiation of complementary feeding using data of child aged 3 to 4 months, while others used wider category of children age that is 6 to 24 months. However, our finding would be higher than the current estimate if we were includes infants aged 6 months.

In the study area we found that significant number of infants was exposed for foods or fluids. Major foods used by mothers as complementary foods were milk other than breast milk (74.5\%) and followed by infant's formula (65\%). But it constitutes plain water, fresh better and glucose (water and sugar). This finding was in line with findings in different part of the country [6]-[10]. It would be explained by the existing infant feeding

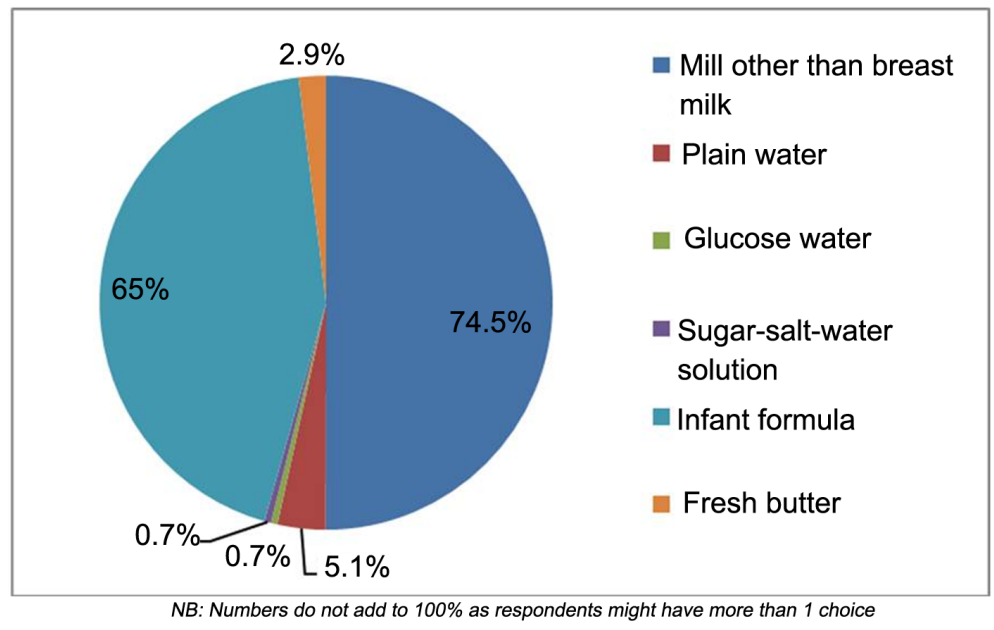

Figure 1. Types of food/drink given to infants in Bishoftu town, February $2015(n=137)$. 
Table 2. Factor associated with early initiation of complementary feeding practices Bishoftu, February 2015.

\begin{tabular}{|c|c|c|c|c|c|}
\hline \multirow[t]{2}{*}{ Variable } & \multirow[t]{2}{*}{ Category } & \multicolumn{2}{|c|}{$\begin{array}{c}\text { Early initiation of } \\
\text { complementary } \\
\text { feeding }\end{array}$} & \multirow[t]{2}{*}{$\mathrm{COR}^{\mathrm{a}} 95 \% \mathrm{CI}$} & \multirow[t]{2}{*}{$\mathrm{AOR}^{\mathrm{b}} 95 \% \mathrm{CI}$} \\
\hline & & Yes & No & & \\
\hline \multirow[t]{4}{*}{ Age of mothers } & $\leq 19$ & 9 & 16 & 1 & \\
\hline & $20-24$ & 19 & 47 & $0.90(0.36,2.23)$ & $0.70(0.24,2.07)$ \\
\hline & $25-29$ & 41 & 103 & $0.70(0.29,1.73)$ & $0.51(0.17,1.50)$ \\
\hline & $30+$ & 50 & 93 & $0.95(0.39,2.32)$ & $0.66(0.23,1.92)$ \\
\hline \multirow[t]{4}{*}{ Educational level of mother } & Illiterate & 18 & 30 & 1 & \\
\hline & $1-8$ & 39 & 116 & $0.56(0.28,1.11)$ & $0.72(0.31,1.64)$ \\
\hline & $9-12$ & 48 & 90 & $0.89(0.45,1.75)$ & $1.42(0.62,3.29)$ \\
\hline & $12+$ & 32 & 49 & $1.08(0.52,2.26)$ & $1.38(0.54,1.85)$ \\
\hline \multirow[t]{2}{*}{ Occupation of mother } & Employed & 66 & 74 & 1 & 1 \\
\hline & Housewives & 71 & 211 & $0.37(0.24,0.57)^{* *}$ & $0.34(0.21,0.55)^{* *}$ \\
\hline \multirow[t]{2}{*}{ Marital status } & Not in union & 10 & 8 & 1 & 1 \\
\hline & Married/in union & 127 & 277 & $0.36(0.14,0.95)^{*}$ & $0.40(0.14,1.14)$ \\
\hline \multirow[t]{2}{*}{ Number of live birth } & 1 & 67 & 133 & 1 & 1 \\
\hline & $>1$ & 70 & 150 & $0.91(0.60,1.37)$ & $0.93(0.55,1.58)$ \\
\hline \multirow[t]{2}{*}{ ANC follow up } & No & 14 & 24 & 1 & 1 \\
\hline & Yes & 123 & 261 & $0.80(0.40,1.61)$ & $0.70(0.31,1.58)$ \\
\hline \multirow[t]{2}{*}{ Delivery type } & Normal vaginal delivery & 117 & 235 & 1 & 1 \\
\hline & Cesarean section & 20 & 50 & $0.80(0.46,1.41)$ & $0.59(0.30,1.14)$ \\
\hline \multirow[t]{2}{*}{ Place of birth } & Home & 10 & 5 & 1 & 1 \\
\hline & Health facility & 127 & 280 & $0.22(0.07,0.67)^{* *}$ & $0.26(0.08,0.89)^{*}$ \\
\hline \multirow[t]{2}{*}{ Own radio } & Yes & 102 & 192 & 1 & 1 \\
\hline & No & 35 & 93 & $0.70(0.45,1.12)$ & $1.02(0.58,1.85)$ \\
\hline \multirow[t]{2}{*}{ Own television } & Yes & 114 & 229 & 1 & 1 \\
\hline & No & 23 & 56 & $0.82(0.48,1.41)$ & $1.07(0.55,2.14)$ \\
\hline \multirow[t]{2}{*}{$\begin{array}{l}\text { Knowledge optimum duration of } \\
\text { EFB }\end{array}$} & Yes & 82 & 243 & 1 & 1 \\
\hline & No & 55 & 42 & $3.88(2.42,6.23)^{* *}$ & $3.91(2.33,6.54)^{* *}$ \\
\hline \multirow[t]{2}{*}{ Age of infant } & $<4$ month & 130 & 272 & 1 & 1 \\
\hline & $4+$ months & 7 & 13 & $1.13(0.44,2.89)$ & $0.69(0.20,2.31)$ \\
\hline \multirow[t]{2}{*}{ Baby’s gender } & Female & 74 & 152 & 1 & 1 \\
\hline & Male & 63 & 133 & $1.02(0.68,1.55)$ & $0.97(0.60,1.57)$ \\
\hline \multirow[t]{2}{*}{$\begin{array}{l}\text { Delayed breastfeeding } \\
\text { initiation }\end{array}$} & Yes & 35 & 18 & 1 & 1 \\
\hline & No & 96 & 267 & $5.41(2.93,9.99)^{* *}$ & $4.76(2.33,6.54)^{* *}$ \\
\hline
\end{tabular}

NB: ${ }^{*} \mathrm{P}$ value $<0.05,{ }^{* *} \mathrm{P}$ value $<0.001$

culture which influences practices of mothers on early initiation of complementary food for infants.

Mothers who delays initiation of breastfeeding was 4.7 times more likely expose their child for complementary food. This could occur due to the fact that mothers who had single birth might lack experience of initiating breastfeeding in a short time after giving birth [9] [10]. 
Mothers who are housewives were $64 \%$ less likely initiate complementary food than their counter part employed mothers. This finding was supported by other research [3] [10], employed mothers lack the time to breastfeed their child. This were due to employed mothers go back to their work after completed their 60 days maternity leave and others were ready for work at 3 month.

Mother who lack the knowledge of recommended optimum duration of exclusive breastfeeding (form birth to six month of life) were up to 4 fold earlier initiate complementary food for their child. This finding was in line with other studies [5] [10] [12].

Mothers who gave birth in the health facilities was $74 \%$ less likely initiate complementary food than those mothers who gave birth at home. This finding was consistent other studies [9] [10]. This could be due to the support mother received form trained delivery attendants and infant food counseling services. This relatively high prevalence of early initiation of complementary feeding at penta-valent three vaccinations can be minimized by health education in the health facility and at the community level.

\section{Limitation of the Study}

The study design was cross sectional so cause and effect relationship could not be established.

\section{Conclusion}

More than one third of mothers (32.5\%) in this study area initiated complementary feeding at the age of 3 to 4 months for their infants. Factors such as employment, place of delivery, knowledge of recommended duration of exclusive breastfeeding, and spending time to initiate breastfeeding following delivery were found to be significantly associated with early initiation of complementary feeding practices of mothers for their infants. Thus it is important to encourage all mothers to deliver their baby in health institutions where they will have a better opportunity to receive counseling on appropriate child feeding practices. Moreover, it is also recommended to create mother-friendly work places and to disseminate appropriate information education and communication (IEC) and Behavioral change communication (BCC) using various mass media outlets to raise awareness on appropriate feeding practices.

\section{Acknowledgements}

We are thankful for all participant mothers for their time and invaluable responses.

\section{Authors' Contribution}

GGD and YB initiate the research, wrote the research proposal, conducted the research, did data entry and analysis. SAB and MDA involved in conceptualization of the research, statistical analysis and writing of the manuscript. All authors read and approved the final manuscript.

\section{References}

[1] UNICEF (2014) Committing to Child Survival: A Promise Renewed Progress Report 2014. United Nations Children Fund: (UNICEF), New York. http://data.unicef.org/corecode/uploads/document6/uploaded_pdfs/corecode/APR-2014-17Oct14-web_194.pdf

[2] WHO (2013) Cause-Specific Mortality Estimates for Major Causes of Child Death for 2000-2013. World Health Organization and Child Health Epidemiology Reference Group. http://www.who.int/healthinfo/global burden disease/estimates child cod 2013/en/

[3] Monte, C.M. and Giugliani, E.R. (2004) Recommendations for the Complementary Feeding of the Breastfed Child. Jornal de Pediatria, $\mathbf{8 0 .}$

[4] WHO (2009) Infant and Young Child Feeding: Model Chapter for Textbooks for Medical Students and Allied Health Professionals. World Health Organization, Geneva.

[5] Shumey, A., Demissie, M. and Berhane, Y. (2013) Timely Initiation of Complementary Feeding and Associated Factors among Children Aged 6 to 12 Months in Northern Ethiopia: An Institution-Based Cross-Sectional Study. BMC Public Health, 13, 1050. http://dx.doi.org/10.1186/1471-2458-13-1050

[6] Becquet, R., Ekouevi, D.K., Viho, I., Sakarovitch, C., Toure, H., Castetbon, K., et al. (2005) Acceptability of Exclusive Breast-Feeding with Early Cessation to Prevent HIV Transmission through Breast Milk. Journal of Acquired Im- 
mune Deficiency Syndromes, 40.

[7] Tamiru, D. (2013) Introduction of Complementary Foods to Infants within the First Six Months and Associated Factors in Rural Communities of Jimma Arjo. International Journal of Nutrition and Food Sciences, 2, 77. http://dx.doi.org/10.11648/j.ijnfs.20130202.18

[8] CSA [Ethiopia] and ICF International (2012) Ethiopian Demographic and Health Survey (EDHS) 2011. Addis Ababa, Ethiopia and Calverton, Maryland, USA.

[9] Asfaw, M.M., Argaw, M.D. and Kefene, Z.K. (2015) Factors Associated with Exclusive Breastfeeding Practice in Debre Berhan District, Central Ethiopia. International Breastfeeding Journal, 10, 23. http://dx.doi.org/10.1186/s13006-015-0049-2

[10] Agedew, E., Demisse, M., Misker, D. and Hailu, D. (2014) Early Initiation of Complementary Feeding and Associated Factors among 6 Month to 2 Years Young Children, in Kamba Woreda, Southwest Ethiopia. Journal of Nutrition \& Food Science, 4, 6. http://dx.doi.org/10.4172/2155-9600.1000314

[11] Scott, J.A., Binns, C.W., Graham, K.I. and Oddy, W.H. (2009) Predictors of the Early Introduction of Solid Foods in Infants: Results of a Cohort Study. BMC Pediatrics, 9, 60. http://dx.doi.org/10.1186/1471-2431-9-60

[12] Vaahtera, M., Kulmala, T., Hietanen, A., Ndekha, M., Cullinan, T., Salin, M.L., et al. (2001) Breastfeeding and Complementary Feeding Practices in Rural Malawi. Acta Paediatrica, 90, 328-332. http://dx.doi.org/10.1111/j.1651-2227.2001.tb00313.x

[13] WHO (2003) Infant and Young Child Feeding: A Tool for Assessing National Practices, Policies and Programmes. World Health Organization, Geneva.

[14] WHO (2008) Indicators for Assessing Infant and Young Child Feeding Practice: Part I. Definitions. Conclusions of a Consensus Meeting Held 6-8 November 2007 in Washington DC, USA. http://whqlibdoc.who.int/publications/2008/9789241596664_eng.pdf?ua=1

[15] WHO (2002) Complementary Feeding: Summary of Guiding Principles. Report of the Global Consultation, 10-13 December 2001. World Health Organization, Geneva. 